\title{
The Development of Pancreatic Function in Premature Infants after Milk-Based and Soy- Based Formulas
}

\author{
EMANUEL LEBENTHAL, ${ }^{(29)}$ TAI-SOON CHOI, AND P. C. LEE \\ Division of Gastroenterology and Nutrition, Division of Neonatology, Department of Pediatrics, State University of \\ New York at Buffalo, and Children's Hospital of Buffalo, Buffalo, New York, USA
}

\begin{abstract}
Summary
Thirty-one premature infants who required nasojejunal feeding were evaluated for pancreatic exocrine function before and after feeding of milk-based or soy-based formulas for $\mathbf{3 0}$ days. The two groups were well matched for age and birth weight (about $1.5 \mathrm{~kg}$ ). At birth, all infants had high basal secretion of trypsin and chymotrypsin, but low lipase and no amylase activity. Additionally, there was no response to pancreozymin (CCK). After 30 days of feeding with either soy or milk-based formulas, both groups showed a similar increase in body weight (to $1.8 \mathrm{~kg}$ ) and basal secretion of trypsin, chymotrypsin, and lipase and failure to secrete amylase. The group that was fed milk-based formula failed to respond to CCK and secretin administration. Thus, soy- and milk-based formulas result in similar weight gain and similar basal pancreatic enzyme secretion while feeding with soy-based formula selectively increases the trypsin and lipase response to CCK.
\end{abstract}

\section{Speculation}

Adaptation of pancreatic exocrine function to dietary modifications has been shown in adults. Such adaptation may also exist in neonates. Feeding of two contrasting formulas, soy and milk based, may affect the development and maturation of the exocrine pancreatic function differently.

In comparison to adults, newborn term and preterm infants suffer a state of digestive insufficiency. Newborns have a less developed pattern of exocrine pancreatic function which is characterized by very low lipase and absence of amylase activities in the duodenal contents $(2,4,8,13,26)$.

Premature infants ( 32 to $34 \mathrm{wk}$ of gestation) absorb only 65 to $75 \%$ of the lipid intake. Full-term newborns absorb 85 to $90 \%$ of the lipid intake, and adult levels of lipid absorption are not attained until 4 to 6 months of age $(12,20)$. Thus, varying degrees of "steatorrhea" can be found in young infants. Starch digestion has not been studied in prematures; however, as measured by the carbohydrate content and composition in the intestinal juice after feeding of a test meal containing amylopectin, infants 3 to 6 months of age suffer diminished starch digestion when compared to children older than 1 year (1). In contrast, both premature and full-term neonates have been found to effectively absorb proteins (2).

Knowledge of the level of pancreatic enzymes in premature infants is scanty (10). In the study by Borgstrom et al (2), premature infants around $1 \mathrm{wk}$ of age were found to have a decreased concentration of trypsin in basal duodenal fluid and a failure of pancreatic response to feeding when compared with infants 14 to 30 days of age. Zoppi et al. (26) found no difference in trypsin activity between premature neonates and full-term neonates. However, very low activities of lipase and alpha-amylase were noted in premature neonates.
In animals, pancreatic enzymes have been shown to be influenced by diet. Diets high in carbohydrate content were found to selectively increase the pancreatic content of amylase in rats (5, 23 ), whereas diets high in protein were shown to result in high trypsin and chymotrypsin contents in the pancreas and intestinal fluid (18). Diets high in fat were found to induce an increase in lipase both in pancreatic content and intestinal luminal content in rats after weaning but not before. In humans, protein-rich diets have been shown to result in high concentrations of trypsin and lipase but not amylase in duodenal fluids of young infants (26). On the other hand, high-fat diets were found to have no effect on pancreatic enzymes in both premature and full-term newborns. The general consensus at present is that an adaptation of pancreatic secretion of digestive enzymes occurs in response to diets of different composition. However, the adaptation requires a prolonged dietary modification for many days or weeks (16).

This study was performed to assess the exocrine pancreatic function of newborn premature infants and to determine whether the maturation of pancreatic function is influenced by infant formula composition.

\section{PATIENTS AND METHODS}

Within a period of $3^{1 / 2}$ years, 52 premature infants born between 28 and 34 wk of gestation were admitted to the study. Assessment of gestational age was done by maturity rating using both external signs and neurologic findings (24). All infants chosen had previously been placed on nasojejunal feeding by the neonatal staff. Of the 52 infants chosen initially for this study, eight developed medical complications such as respiratory distress syndrome, diarrhea, and sepsis. Seven did not gain sufficient weight while on soy-based formula (Isomil and Prosobee), and six did not gain weight on milk-based formula (Similac or Enfamil). Prematures in the latter two groups were switched to human milk with supplement of Enfamil premature formula (Mead Johnson) or parenteral hyperalimentation and were not included in the study. Of the 31 infants who completed the study, 16 infants were fed only milk-based formula, and 15 were fed only soy-based formula for 30 days, which was the duration of the study. The major components in the soy-based formula (Isomil and Prosobee) and the cow's milk-based formula (Similac and Enfamil) are listed in Table 1 .

Because results from infants fed either Isomil or Prosobee were the same, they were presented as a group under soy-based formulas. Similarly, those fed on either Similac or Enfamil were identical and therefore were also presented as a group under milkbased formula. The daily intake of formula and weight gain for each infant were recorded. The weight of each infant at birth and at 30 days of age is presented in Tables 3 and 4. Pancreozyminsecretin test was performed on each subject in the first 3 days of life before oral feeding and also at 30 days of age. The protocol for this investigation was approved by the Human Research 
Table 1. Composition of major components in various formulas

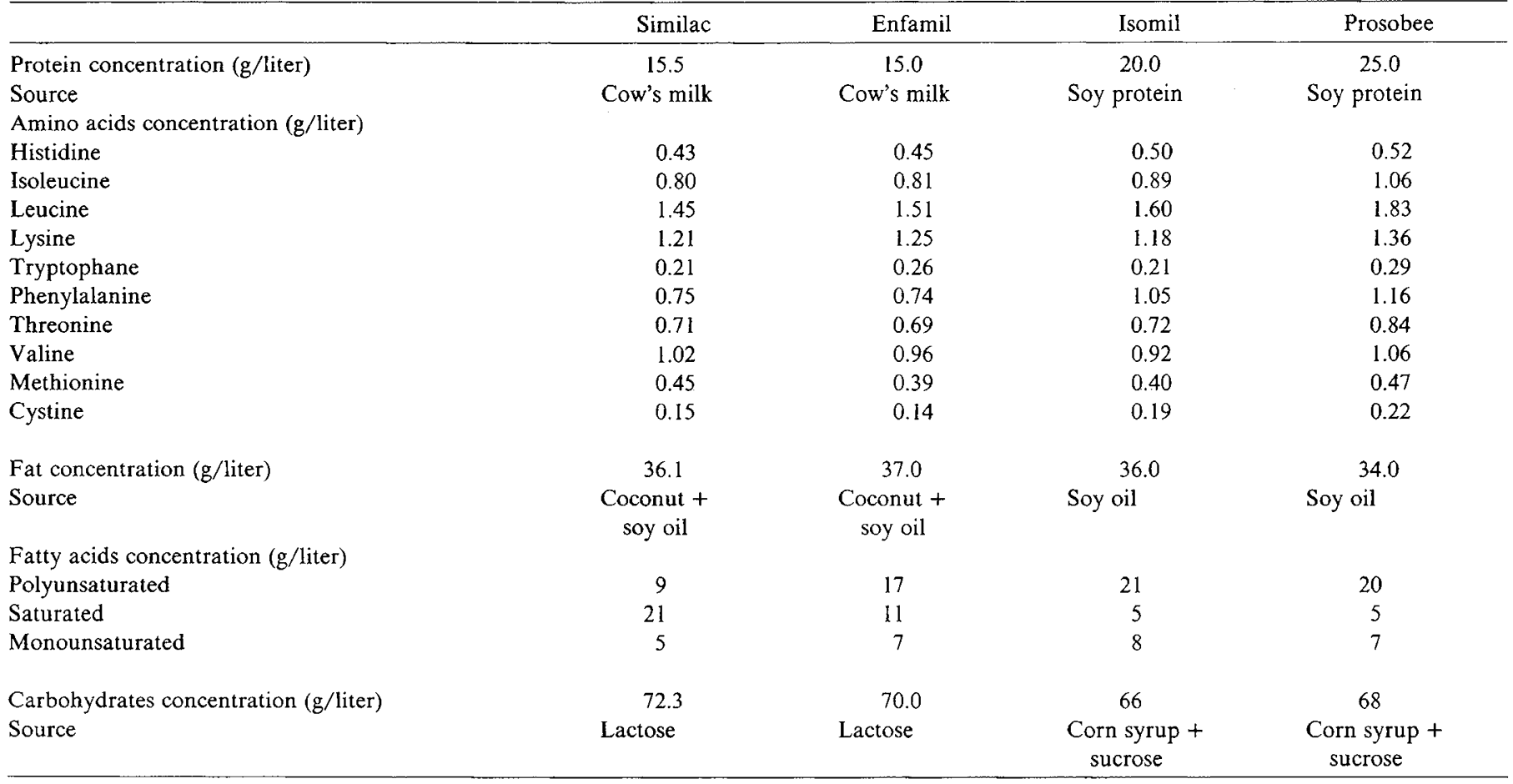

Committee of the Children's Hospital of Buffalo. After proper explanation, written consent was given by all parents.

\section{PANCREOZYMIN-SECRETIN TEST}

The test used was a slight modification of that reported by Zoppi et al. (26). All tests were performed in the morning after a 4- to 6-hr fast. In addition to the nasojejunal tube already present, an additional gastric tube was placed. The correct position of the nasojejunal tube was assessed by the yellowish-green color and basic $\mathrm{pH}$ of the fluid collected. Two 10-min basal duodenal fluid specimens were collected. Pancreozymin (CCK-PZ, Kabi Diagnostica) was injected IV at a dosage of 2 units/ $\mathrm{kg}$ body weight. One 30-min collection was obtained. Secretin (Kabi Diagnostica) was then injected IV also at the dosage of 2 units $/ \mathrm{kg}$ body weight. An additional 30 -min collection was performed. All fluid specimens were collected over ice. They were stored at $-20^{\circ} \mathrm{C}$ for subsequent enzyme determination. During the entire test, the $\mathrm{pH}$ of all samples was monitored to insure a correct tube placement.

\section{ENZYME DETERMINATION}

Enzyme assays were performed as soon as possible after collection (within $24 \mathrm{hr}$ ). Enzyme activities did not change appreciably after one freeze and thaw cycle.

Trypsin (EC 3.4.4.4) activity was measured by the liberation of $p$-nitroaniline from the substrate benzoyl-DL-arginine- $p$-nitroaniline at $\mathrm{pH} 8.2$ and $25^{\circ} \mathrm{C}$ according to the method of Erlanger et al. (7). Units were expressed as nmoles of $p$-nitroaniline produced per minute.

Chymotrypsin (EC 3.4.4.5) was determined from the rate of hydrolysis of $N$-benzoyl-DL-tyrosin ethyl acetate ester as measured by the change in absorbance at $256 \mathrm{~nm}$ with time, as described by Hummel (11). Units were expressed as micromoles of substrate hydrolyzed per minute.

Lipase (EC 3.1.1.3) activity was determined by the potentiometric titration (at a constant $\mathrm{pH}$ 8.0) of ionized fatty acids liberated from a triglyceride (olive oil) emulsion with $0.05 \mathrm{~N}$ $\mathrm{NaOH}$ following the procedures of Smeriva et al. (22). Units were expressed as mmoles of acid equivalent liberated per minute. This measures only the lipase activity independent of the colipase activities.
Alpha-amylase (EC 3.2.1.1) was determined from the colored product obtained by the reduction of 3,5 dinitrosalicylic acid by maltose liberated in the hydrolysis of starch (21).

Lowry et al.'s method (18), with a Folin phenol reagent and bovine serum albumin as the standard, was used to derive the amount of total protein.

\section{RESULTS}

Tables 2 and 3 list the premature infants with their gestational ages, birth weights, and 30-day weights after feeding on milk- or soy-based formula. There were no statistical difference in the two groups of infants for gestational ages and birth weights. Their average daily intake of infant formula during the 30 days of the study was also comparable. The average body weights of the two groups of infants after 30 days were also similar. The average daily weight gain in the group who were fed soy-based formula (Table 3 , fourth column) was slightly lower than, but statistically insignificant from, the average daily weight gain of the group fed milk-based formula (Table 2, fourth column).

Protein concentration, amylase, trypsin, chymotrypsin, and lipase were measured in the duodenal fluids of neonatal premature infants ( 1 to 3 days old). Table 4 summarizes the results. Amylase was not detected. Basal trypsin and chymotrypsin activities were moderate [ 20 to $25 \%$ of adult level (17)]. Lipase was low $[<5 \%$ of adult level (17)]. The protein concentration, trypsin, chymotrypsin, and lipase activities did not change after pancreozymin and secretin administration. There were no differences between infants that were to be fed milk-based formula (group $M$ ) and infants that were to be fed soy-based formula (group S).

Table 5 shows the results obtained from the same groups of infants fed for 30 days with milk-based formula (group M) or with soy-based formula (group S). Protein concentrations in the duodenal fluids did not change significantly compared to the values in the 3 day olds (Table 4). No significant difference was found between the protein concentration in the duodenal fluid of the $\mathrm{M}$ and $\mathrm{S}$ groups before and after $(\mathrm{CCK})$ and secretin administrations.

Basal levels of trypsin, chymotrypsin, and lipase in the duodenal fluids of all infants fed with formula for 30 days (Table 5) showed significant increase compared to the basal values of the neonates (Table 4). There was no significant difference between the corre- 
Table 2. Growth of infants after 30 days feeding on milk-based formula

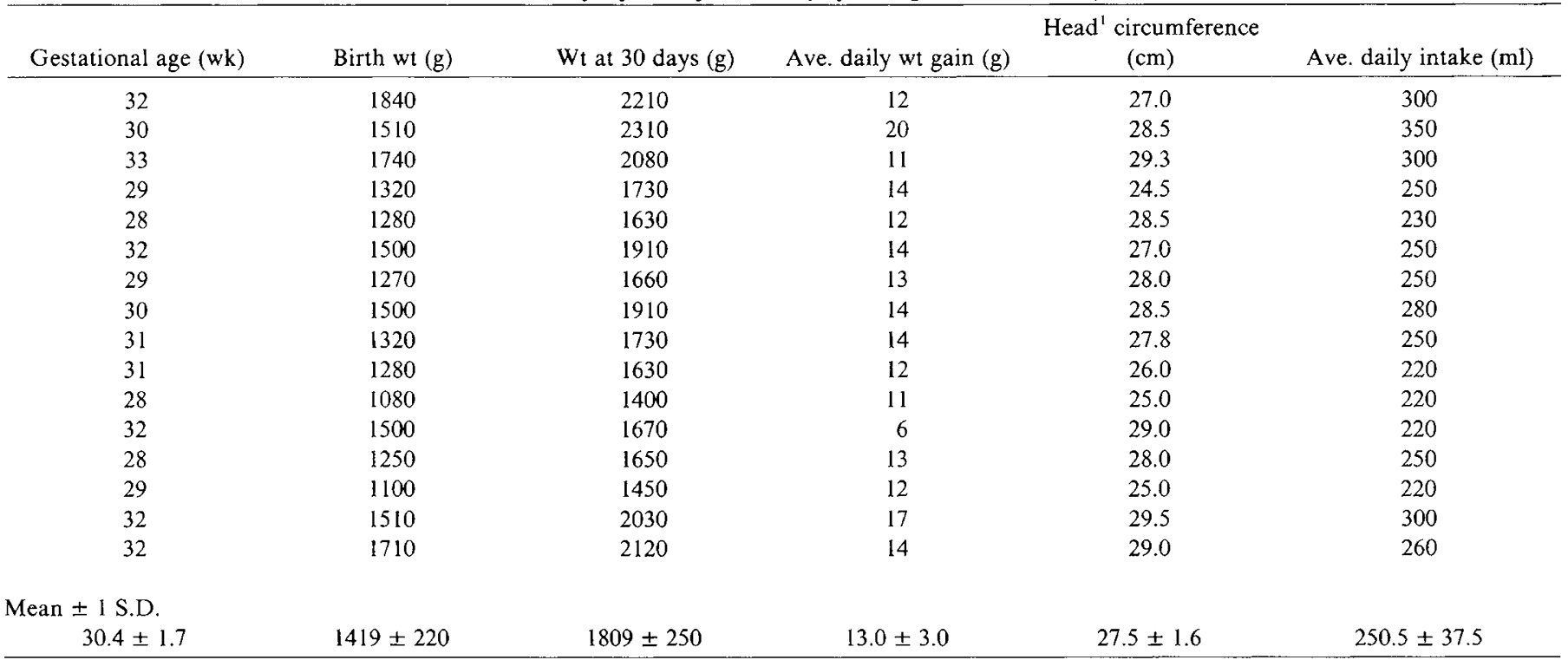

${ }^{1}$ Measured at the time of birth.

Table 3. Growth of infants after 30 days feeding on soy-based formula

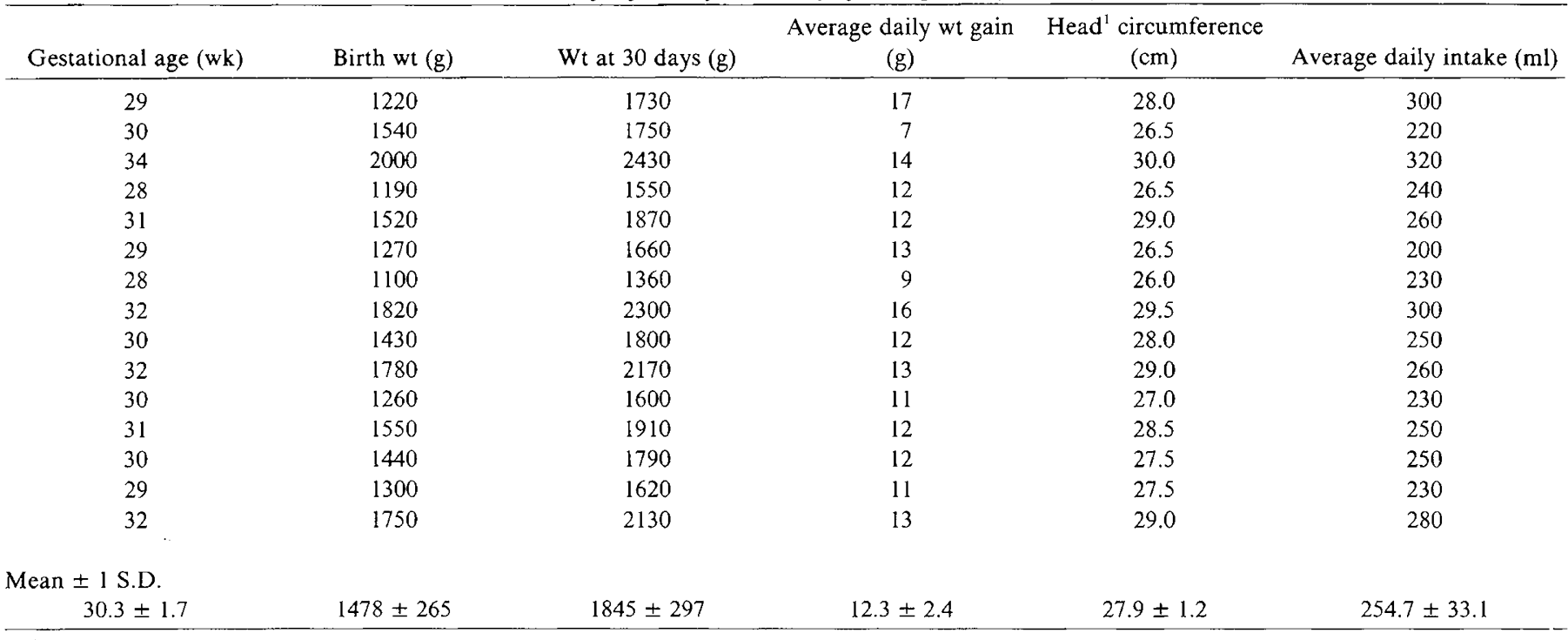

${ }^{1}$ Measured at the time of birth.

Table 4. Effect of pancreozymin and secretin on pancreatic secretion in two groups of premature infants before feeding

\begin{tabular}{l} 
r \\
\cline { 2 - 6 }
\end{tabular}


Table 5. Effect of pancreozymin (CCK) and secretin pancreatic secretion in two groups of premature infants after 30 days of feeding with milk-based formula (group " $M$ ") or soy-based formula (group " $S$ ")

Enzyme activities (unit/mg protein)

\begin{tabular}{|c|c|c|c|c|c|c|c|c|}
\hline & \multicolumn{2}{|c|}{ Protein $(\mathrm{mg} / \mathrm{ml})$} & \multicolumn{2}{|c|}{ Trypsin } & \multicolumn{2}{|c|}{ Chymotrypsin } & \multicolumn{2}{|c|}{ Lipase } \\
\hline & $M^{3}$ & $\mathrm{~S}$ & M & $S$ & M & $\mathrm{S}$ & M & $\mathrm{S}$ \\
\hline Basal & $4.4 \pm 0.8^{2}$ & $4.7 \pm 0.8$ & $31.9 \pm 5.1$ & $31.1 \pm 4.2$ & $0.69 \pm 0.07$ & $0.52 \pm 0.06$ & $1.97 \pm 0.43$ & $2.14 \pm 0.43$ \\
\hline CCK-PZ & $3.9 \pm 0.7$ & $4.4 \pm 1.0$ & $27.5 \pm 4.1^{3}$ & $40.4 \pm 5.4^{3,4}$ & $0.73 \pm 0.14$ & $0.62 \pm 0.19$ & $2.11 \pm 0.6$ & $3.06 \pm 0: 42^{3,4}$ \\
\hline Secretin & $4.2 \pm 1.0$ & $4.4 \pm 0.9$ & $29.3 \pm 4.0$ & $37.6 \pm 5.7^{3.4}$ & $0.56 \pm 0.13^{3}$ & $0.55 \pm 0.11$ & $2.02 \pm 0.54$ & $3.62 \pm 0.87^{3.4}$ \\
\hline
\end{tabular}

${ }^{1} \mathrm{M},(N N=16)$ refers to the group of infants fed only milk-based formula for 30 days from birth; $\mathrm{S},(N=15)$ refers to group of infants fed only soybased formula for 30 days from birth.

${ }^{2}$ Mean \pm I S.D. of protein concentrations or enzyme activities in duodenal fluid.

${ }^{3}$ Values significantly different $(P<0.01)$ from the corresponding basal values by Student's $t$ test.

${ }^{4}$ Values significantly different $(P<0.01)$ from the corresponding values after CCK-PZ (pancreozymin) or secretin administration from the " $\mathrm{M}$ " group by Student's $t$ test.

infants fed milk-based formula, but it substantially increased the trypsin level in the duodenal fluids from the group of infants fed soy-based formula. Again, this level was significantly higher than the corresponding value from infants fed the milk-based formula.

The chymotrypsin activity in the duodenal fluid remained the same after pancreozymin (CCK) administration in both the $\mathrm{M}$ and $\mathrm{S}$ groups. After secretin administration, the chymotrypsin level in the duodenal fluids of the $M$ group was significantly reduced. In the $S$ group, secretin did not affect the chymotrypsin level in the duodenal fluid. Furthermore, the chymotrypsin level was not significantly different from the corresponding value in the $M$ group.

Pancreozymin (CCK) and secretin had no effect on the lipase activities in the duodenal fluids of the group of infants fed milkbased formula, but significantly higher lipase levels were observed in the $S$ group than in the $M$ group after pancreozyjin (CCK) or secretin.

No detectable amylase could be measured in the duodenal fluids before and after PS test from any of the infants in either group after 30 days feeding with the corresponding formula.

\section{DISCUSSION}

Pancreatic exocrine function has been shown to be influenced by diet composition. The general consensus is that high-protein diet results in a higher content of proteases in the pancreas and in the pancreatic secretion than a low protein diet (26). A diet high in starch leads to a higher level of amylase as compared to a low or a starch-free diet $(16,26)$. High lipid diets may lead to increase (13) or no change (23) in lipase activities.

Developmentally, it has been reported that pancreases from fetal and neonatal rats are lacking in response to stimulation by secretogogues $(6,15,25)$. Similarly, we have shown a lack of response of the newborn human pancreas to pancreozymin (16) together with a low level of lipase and absence of amylase secretion. Our present study confirms these observations.

The results show that 1 - to 3 -day-old premature infants $(28$ to 34 wk of gestation) appear to have limited pancreatic function: low basal levels of lipase, chymotrypsin, and trypsin; complete absence of amylase; and a general lack of responsiveness to pancreozymin and a limited response to secretin. Increase in pancreatic secretion occurred when these infants were measured after 30 days irrespective of the type of formulas fed.

Barring any genetic variations, the major difference between the two groups of 30-day-old premature infants was in their dietary formula. One group has been fed a cow's milk-based formula only and the other, a soy-based formula only. Besides the basic difference in their protein sources, the soy-based formula has a higher protein content ( 20 to $25 \mathrm{~g} /$ liter) than milk-based formula ( 15.0 to $15.5 \mathrm{~g}$ /liter). Although the milk-based formula contains lactose almost exclusively as the carbohydrate source, the soy-based formula has polysaccharides up to $3 \%$ by weight plus
$3 \%$ sucrose and about $1 \%$ of mono-, di-, and tri-saccharides (27, 28). The amount of fat, caloric content, and osmolality in both formulas are fairly comparable.

Our results indicated that there was no difference in the basal secretion of pancreatic enzymes between the two groups of infants after feeding with soy or milk-based formula for 30 days. Both groups showed a significant increase in all enzymes except amylase over the 1 to 3 -day-old levels. No difference in growth measured by the weight gain was evident between the groups. Thus, both formulas seemed to be able to support general body growth and basal pancreatic enzyme secretion. However, feeding with soybased formula resulted in a significant and selective increase in trypsin and lipase response to pancreozymin and secretin compared to feeding with milk-based formula.

Dietary influence on pancreatic exocrine function, including an increase in amylase following a starch diet, has been reported by Zoppi et al. (26). In their study, only basal secretion was measured, and no data were available on the secretion of enzymes after stimulation with pancreozymin and secretin. In the present study, we observed no difference in the basal duodenal content of trypsin, chymotrypsin, and lipase between the group fed with soy-based formula (higher in protein and polysaccharide) and the group fed with milk-based formula. One explanation for the absence of an inductive effect on the basal levels of proteases may be that the difference in the protein content (20 versus $15.5 \mathrm{~g} /$ liter) was not sufficient to affect a differential production of proteases in the pancreases of the two groups of infants. The absence of detectable amylase in our study was of special concern because the amount of polysaccharides in the soy-based formula is comparable to that used by Zoppi et al. (26) where induction of amylase was reported. It is possible that the small amount of amylase (about $1.6 \%$ of the adult level) measured by Zoppi et al. was salivary in origin. Alternatively, the induction of amylase may specifically require starch. Polysaccharides in the soy-based formula are from corn syrup and have degree of polymerization less than starch and hence not effective.

The observed increase in trypsin and lipase response to pancreozymin and secretin after feeding for 30 days with soy-based formula is interesting. The effect of soy-based formula on trypsin is more likely due to a difference in the type than the amount of the protein because the effect was specific for trypsin and not for chymotrypsin. The effect of soybean trypsin inhibitor in the soybased formula has been considered. The estimated quantity of active trypsin inhibitor in the formula (3), calculated to be about 5 units/g of diet was much lower than the concentration (25 units/ $\mathrm{g}$ of diet) that was found to increase the trypsin content in the pancreas (14) and, therefore, should not affect trypsin activity significantly. The increase in lipase in response to pancreozymin and secretin in the group fed soy-based formula may be related to the higher content of polyunsaturated fatty acids in these formulas, because it has been suggested that the type of dietary fat exerts a marked effect in the lipase content of the pancreas in the rat (9). 
In conclusion, premature infants exhibit low exocrine pancreatic function which increases during postnatal development. Both cow's milk-based formula and soy-based formula permit development in general and specifically to the development of pancreatic enzymes. Soy-based formula appears to promote a more rapid maturation of pancreatic exocrine function especially the lipase and trypsin response to pancreozymin (CCK).

\section{REFERENCES AND NOTES}

1. Auricchio, S., Della Pietra, D., and Vegnente A: Studies on intestinal digestion of starch in man. II. Intestinal hydrolysis of amylopectin in infants and children. Pediatrics, 39: 853 (1867).

2. Borgstrom, B., Lindquist, B.. and Lundh. G.: Enzyme concentration and absorption of protein and glucose in duodenum of premature infants. Am. J. Dig. Dis., 99: 338 (1960).

3. Churella, H. R.. Yao B. C., and Thomson W. A. B.: Soybean trypsin inhibitor activity of soy infant formulas and its nutritional significance for the rat. Agric Food Chem., 24: 293 (1976).

4. Delachaume-Salem, E., and Sarles, H.: Normal human pancreatic secretion in relation to age. Biol. Gastro-Enterol., 59: 136 (1970).

5. Deschodt-Lanckman, M., Robberecht, P.. Camus, J., et al.: Hormonal and dietary adaptation of rat pancreatic hydrolases before and after weaning. Am. $\mathbf{J}$ Physiol., 226: 39, (1974).

6. Doyle. C. M., and Jamieson, J. D.: Development of secretogogue response in rat pancreatic acinar cells. Dev. Biol., 65: 11 (1978).

7. Erlanger. B. F., Kokowsky, N., and Cohen, W.: The preparation and properties of two new chromogenic substrates of trypsin. Arch. Biochem. Biophys., 95: 271 (1961).

8. Farber. S., Shwachman, H., and Maddock. C.L.: Pancreatic function and disease in early life. I. Pancreatic enzyme activity and the celiac syndrome. J. Clin. Invest., 22: 827 (1943).

9. Gidez, L. I.: Effect of dietary fat on pancreatic lipase levels in the rat. J. Lipid Res., 14: 169 (1973).

10. Gryboski, J.: Gastrointestinal problems in the infant. The pancreas. In: Major Problems in Clinical Pediatrics. Vol. 12, p. 40 (W. B. Saunders Co., Philadelphia, PA, 1975).

11. Humel, B. C.: Modified spectrophotometric determination of chymotrypsin, trypsin and thrombin. Can. J. Biochem. Physiol., 37: 1393 (1959).

12. Katz, L., and Hamilton, J. R.: Fat absorption in infants of birth weight less than 1300 grams. J. Pediatr., 85: 608 (1974)

13. Klumpp. T. C., and Neale, A. V.: The gastric and duodenal contents of normal infants and children. Am. J. Dis. Child., 40:1215 (1930).

14. Konijn. A. M. Birk, Y., and Guggenheim, K.: In vitro synthesis of pancreatic enzymes: effects of soybean trypsin inhibitor. Am. J. Physiol., 218: 1113 (1970).

15. Larose, L., and Morriset $\mathrm{J}$; Acinar cell responsiveness to urecholine in the rat pancreas during fetal and early postnatal growth. Gastroenterology, 73: 530 (1977).

16. Lebenthal, E.: Pancreatic function and disease in infancy and childhood. Adv. Pediatr., 25: 223 (1978).

17. Lebenthal, E., and Lee, P.C.: Development of functional response in human exocrine pancreas. Pediatrics, 66: 556 (1980)

18. Lowry, O. H., Rosebrough, N. J., Fars, A. L., and Randall, R. J.: Protein measurement with the Folin phenol reagent. J. Biol. Chem., 193: 265 (1951).

19. Robberecht, P. Deschodt-Lanckman, M. Camus, J. et al. Rat pancreatic hydrolases from birth to weaning and dietary adaptation after weaning. Am. J. Physiol., 221: 376 (1971).

20. Roy, C.C., Ste-Marie, M., Chartrand, L., et al:: Correction of the malabsorption of the preterm infant with a medium chain triglyceride formula. J. Pediatr., 86 : 446 (1975).

21. Searcy, R. L., Hayaski, S., and Berk, T. E.: A new microsaccharogenic method for serum amylase determination. Tech. Bull. Regist. Med. Technol. 36: 252 (1966).

22. Smeriva, M., Dufour, C., and Desnuelle, P.: On the probable involvement of a histidine residue in the active site of pancreatic lipase. Biochemistry, 10:2143 (1971).

23. Snook, J. T.: Effect of diet on development of exocrine pancreas of the neonatal rat. Am. J. Physiol., 221: 1388 (1971).

24. Sweet, A. Y.: Classification of the low-birth-weight infants, In: M. H. Klaus, A. A. Fanaroff: Care of the High Risk Infants. (W. B. Saunders Co., Philadelphia, PA, 1977).

25. Werlin, S. L., and Grand, R. J.: Development of secretogogue response in rat pancreas. Am. J. Physiol., 236: E446 (1979).

26. Zoppi, G., Andreotti, G., Pajno-Ferrara, F., et al.: Exocrine pancreas function in premature and full term infants. Pediatr. Res., 6: 880 (1972).

27. Cow milk allergy. Lactose Intolerance. Ross Laboratories Publication, 1976.

28. Milk-based and soy-based formulations. Ross Laboratories Publication, 1979.

29. Requests for reprints should be addressed to: Emanual Lebenthal, Division of Gastroenterology and Nutrition, Children's Hospital of Buffalo, 219 Bryant Street, Buffalo, NY 14222 (USA).

30. This research was supported in part by a grant in aid from Mead Johnson Company and Ross Laboratories who provided the soy- and milk-based formulas.

31. Received for publication June 6, 1980

32. Accepted for publication February 2, 1981. 